\title{
Applicability of chromosome-specific SSR wheat markers for the introgression of Triticum urartu in durum wheat breeding programmes
}

\author{
C. Rodríguez-Suárez*, M. C. Ramírez, A. Martín and S. G. Atienza \\ Instituto de Agricultura Sostenible, IAS-CSIC, Apdo. 4084, 14080 Córdoba, Spain
}

Received 2 February 2011; Accepted 15 March 2011 - First published online 20 April 2011

\begin{abstract}
Triticum urartu, the A-genome donor of tetraploid and hexaploid wheats, is a potential source of novel alleles for crop improvement. A fertile amphiploid between T. urartu $(2 n=2 x=14$; $\mathbf{A}^{\mathbf{u}} \mathbf{A}^{\mathbf{u}}$ ) and durum wheat $\mathrm{cv}$ 'Yavaros' (Triticum turgidum ssp. durum; $2 n=4 x=28$, AABB) was obtained as a first step to making the genetic variability of the wild ancestor available to durum wheat breeding. The amphiploid was backcrossed with 'Yavaros' and the offspring from this cross was selfed. A plant from this progeny (founder line) with 28 chromosomes and active $x$ and $y$ subunits of the Glu-A1 locus of T. urartu was selfed, which resulted in the obtaining of 98 pre-introgression lines (pre-ILs). In this work, a set of 78 wheat chromosome-specific microsatellite markers (simple sequence repeats, SSR), uniformly distributed over the A genome, was used for marker-assisted selection of T. urartu in a durum wheat background. A total of 57 SSRs allowed a clear discrimination between T. urartu and 'Yavaros'. This set of markers was further used for characterizing the pre-ILs, identifying and defining the T. urartu introgressed regions. The applicability of these markers is discussed.
\end{abstract}

Keywords: introgressions lines; marker assisted selection; simple sequence repeats; Triticum urartu

\section{Introduction}

Reduction of genetic variability in many crops is becoming a serious threat to the future of agriculture. Selection pressure exerted by humans during domestication has caused bottlenecks that have led to a progressive narrowing of the genetic base in the most important staple crops (Tanksley and McCouch, 1997; Warburton et al., 2006). Increasing variability is a major objective in plant breeding. Regarding wheat, primitive ancestors or wild relatives reveal themselves to be underutilized sources of genetic variability. Among synthetic wheats (proceeding from crosses between durum wheat and the wild goat grass Aegilops tauschii), several have shown promising

*Corresponding author. E-mail: crodriguez@ias.csic.es combinations resulting in higher yields, larger grains and new resistance or tolerance to abiotic and biotic stresses (van Ginkel and Ogbonnaya, 2007). The potential of $A$. tauschii, the D-genome donor of bread wheat, has also been studied for the improvement of quantitative traits in bread wheat (Börner et al., 2002; Huang et al., 2003, 2004; Pestsova et al., 2006). Wild species are also potential donors of exotic alleles for specific traits such as the leaf rust resistance in Lophopyrum ponticum (Podp.) Löve (Zhang et al., 2005) or the high carotenoid content in Hordeum chilense Roem et Schultz. (Atienza et al., 2004; Atienza et al., 2007a, b; Rodríguez-Suárez et al., 2010).

Durum wheat (Triticum turgidum, $2 n=4 x=28$, AABB) can also benefit from ancient wheats and wild species. The interest in so-called ancient wheats such as rivet wheat (T. turgidum L. spp. turgidum) or khorasan wheat (T. turgidum spp. turanicum Jakubz em. A. Löve \& D. Löve) has increased in the last few years (Piergiovanni, 
2009; Xu et al., 2009; Carmona et al., 2010). However, the variability available in the diploid progenitor of durum wheat has been mostly neglected to date. The allotetraploid durum wheat arose by amphiploidization between the wild diploid wheat Triticum urartu $\left(2 n=2 x=14, \mathbf{A}^{\mathbf{u}} \mathbf{A}^{\mathbf{u}}\right)$ and an unknown diploid member of the Aegilops genus $(2 n=2 x=14, \mathbf{B B})$, T. urartu being the A-genome donor of tetraploid and hexaploid wheats (Chapman et al., 1976). Thus, the $\mathrm{A}^{\mathrm{u}}$ genome is a near relative of the A genome, that may be a source of novel alleles lost during domestication as happens with other crops such as barley and its wild relative Hordeum vulgare subsp. spontaneum (Fetch et al., 2003; Yun et al., 2005). Unlike barley, where both the wild and the cultivated species are diploid, durum wheat and T. urartu differ in the ploidy level, and, therefore, the variability of the latter cannot be used directly for durum wheat breeding. Hence, T. urartu has not been exploited for durum wheat improvement up to now even though it shows variability for many important agronomical traits such as endosperm storage proteins or resistance to biotic and abiotic stresses (di Pietro et al., 1998; Qiu et al., 2005; Martín et al., 2008). T. urartu would be an accessible source of wild variation to durum wheat. However, plant breeders know that agronomic performance suffers when exotic germplasm is introgressed into elite germplasm, which is attributed to epistasis and (or) linkage drag (Young and Tanksley, 1989; Lee, 1998; Brondani et al., 2002). As proposed by Eshed and Zamir (1994), introgression lines (ILs) are an efficient resource to overcome these problems and to use the genetic potential of wild species in an effective way, allowing the detection of single traits or QTLs and their easy transfer into new materials.

In a previous work, the synthesis of the amphiploid between T. urartu and durum wheat cv. 'Yavaros' was reported (Alvarez et al., 2009). Storage endosperm proteins (Glu-A1 locus) were effectively used for selecting towards durum wheat lines carrying T. urartu chromatin, and a subset of 20 pre-ILs was analyzed for some quality characters such as grain colour or gluten strength. However, the precise characterization of the introgression lines requires a wider set of molecular markers evenly distributed across the entire genome. Therefore, the objective of this work was to establish an effective set of molecular markers which would be useful for our pre-breeding programme that aims to use T. urartu for durum wheat breeding.

\section{Material and methods}

\section{Plant material}

Durum wheat cv. 'Yavaros', T. urartu accession MG26992, the amphiploid derived from the cross Yavaros $X$
MG26992 and 98 pre-ILs were used. The strategy followed by Alvarez et al. (2009) for the development of the pre-ILs is summarized in Fig. 1.

\section{DNA isolation and simple sequence repeats analyses}

Leaf tissue of 'Yavaros', T. urartu, the amphiploid and the 98 pre-ILs was harvested, frozen in liquid nitrogen and stored at $-80^{\circ} \mathrm{C}$ until DNA extraction. Genomic DNA was extracted according to Murray and Thompson (1980).

The amplification of 78 chromosome-specific simple sequence repeats (SSRs) from different sources was analyzed in the parents and in the amphiploid (Röder et al., 1998; Somers et al., 2004; Sourdille et al., 2004). PCR reactions were performed in a total $25 \mu$ l reaction mixture consisting of $50 \mathrm{ng}$ of genomic DNA, 0.6 U of Taq (Biotools B\&M Labs, Madrid), $1 \mathrm{x}$ PCR buffer, $1.6 \mathrm{mM} \mathrm{MgCl}_{2}$, $0.32 \mathrm{mM}$ dNTPs (Promega, Madison, WI, USA) and $0.6 \mu \mathrm{M}$ of each primer. PCR amplifications were optimized changing the number of cycles $(n)$ and the annealing temperature using one of these two profiles: (1) an initial step of $94^{\circ} \mathrm{C}$ for $3 \mathrm{~min}$, and then $n$ cycles of $94^{\circ} \mathrm{C}$ for $1 \mathrm{~min}, 1 \mathrm{~min}$ at an annealing temperature ranging from 62 to $50^{\circ} \mathrm{C}$ and $72^{\circ} \mathrm{C}$ for $2 \mathrm{~min}$, followed by $10 \mathrm{~min}$ at $72^{\circ} \mathrm{C}$ or (2) an initial step of $94^{\circ} \mathrm{C}$ for $5 \mathrm{~min}$ and then

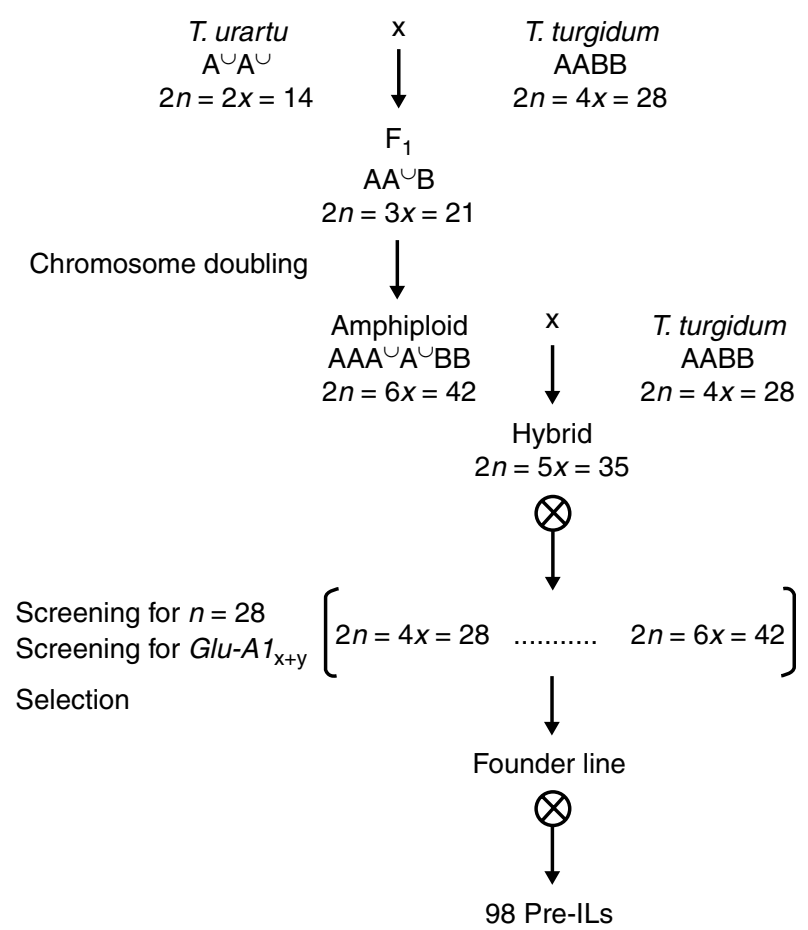

Fig. 1. Development of the amphiploid between T. urartu and durum wheat and construction of the pre-introgression lines, as followed by Alvarez et al. (2009). 
$n$ cycles of $94^{\circ} \mathrm{C}$ for $30 \mathrm{~s}, 30 \mathrm{~s}$ at an annealing temperature ranging from 60 to $50^{\circ} \mathrm{C}$ and $72^{\circ} \mathrm{C}$ for $30 \mathrm{~s}$, followed by $10 \mathrm{~min}$ at $72^{\circ} \mathrm{C}$. PCR products were resolved on $2 \%$ agarose gels, stained with ethidium bromide and visualized under UV light.

\section{Results}

\section{Selection of SSRs and optimization of PCR amplifications}

A set of 78 wheat SSRs uniformly distributed over the A genome was selected for searching for polymorphism between 'Yavaros' and T. urartu (Supplementary Table S1, available online only at http://journals.cambridge. org). All markers (except for Xwmc658) are physically mapped to one breakpoint interval of chromosomes $1 \mathrm{~A}$ to $7 \mathrm{~A}$ in the Chinese Spring deletion lines (Sourdille et al., 2004). Ten to twelve SSRs were tested for each chromosome. Different PCR profiles were assayed using agarose to find polymorphism between alleles in chromosomes $\mathrm{A}^{\mathrm{u}}$ and A from T. urartu and 'Yavaros', respectively.

Twelve SSR markers (Xgwm328, Xgwm512, XBARC208, XBARC12, XBARC54, Xgwm32, XBARC1048, XBARC1047, XBARC153, Xcfa2187, XBARC165 and Xcfd82) did not show any clear and reproducible amplification pattern in our materials under different conditions and were not used further. Nine SSR markers (XBARC19, Xgwm480, XBARC78, XBARC186, Xgwm334,
XBARC37, XBARC1088, Xcfa2028 and Xcfa2257) were monomorphic between T. urartu and 'Yavaros' under different amplification conditions in agarose. Finally, a set of 57 informative and reliable SSRs showing polymorphism between T. urartu and 'Yavaros' and covering the whole A genome was selected. Table 1 shows these SSR markers indicating the optimal PCR profile (see material and methods), number of cycles and annealing temperature.

\section{Molecular characterization of pre-ILs}

The utility of the 57 selected SSRs for our marker-assisted selection programme was assessed in the set of 98 pre-ILs previously obtained (Supplementary Table S2, available online only at http://journals.cambridge.org). For six SSRs, the allele from T. urartu was present in all the pre-ILs (see SSR marker Xwmc658 in Fig. 2(d)). The allele from 'Yavaros' was present in all the pre-ILs at 35 SSR loci (see Xgwm674 in Fig. 2(c)). The remaining 16 polymorphic SSRs were segregating in the pre-ILs (see XBARC108 and Xgwm136 in Fig. 2(a),(b), respectively). Table 1 shows this information for each of the SSR markers. These results are also summarized in Table 2, where the exotic germplasm introgressed in 'Yavaros' is inferred by the presence of T. urartu alleles at each polymorphic loci analyzed. For chromosome 1A, it was possible to identify alleles proceeding from T. urartu for 100\% of the SSRs tested within the set of pre-ILs. For chromosomes $2 \mathrm{~A}$ and $7 \mathrm{~A}$, approximately at $50 \%$ of the loci

Table 1. A set of 57 selected SSR markers ${ }^{\mathrm{a}}$

\begin{tabular}{|c|c|c|c|}
\hline SSR & $P$ & $T^{\mathrm{m}}$ & $n$ \\
\hline XBARC108 & 1 & 50 & 30 \\
\hline 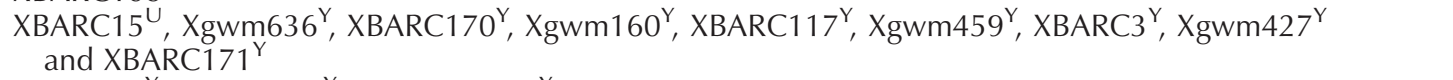 & 1 & 52 & 45 \\
\hline XBARC67, XBARC $106^{Y}$ and $X g w m 276^{Y}$ & 1 & 54 & 45 \\
\hline 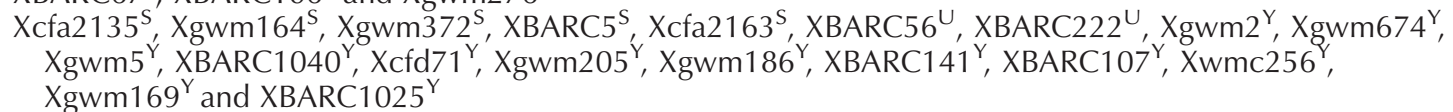 & 1 & 55 & 45 \\
\hline Xgwm $359^{\mathrm{Y}}$ & 1 & 56 & 40 \\
\hline Xgwm $445^{\mathrm{S}}$ and $\mathrm{Xgwm} 415^{\mathrm{Y}}$ & 1 & 56 & 45 \\
\hline Xgwm155, Xgwm $356^{\mathrm{Y}}$ and Xgwm637 $7^{\mathrm{Y}}$ & 2 & 58 & 30 \\
\hline 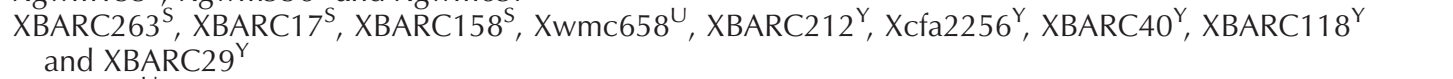 & 1 & 58 & 45 \\
\hline Xcfa2049u & 2 & 60 & 35 \\
\hline Xcfa2153 ${ }^{S}$ and Xcfa2155 & 2 & 60 & 40 \\
\hline Xgwm $136^{\mathrm{S}}, \mathrm{Xgwm} 99^{\mathrm{S}}$ and XBARC1052 $\mathrm{Y}$ & 1 & 60 & 45 \\
\hline XBARC2 $8^{\mathrm{S}^{\prime}}$ and Xgwm $391^{\mathrm{Y}}$ & 1 & 62 & 35 \\
\hline $\mathrm{Xgwm} 60^{\mathrm{U}}$ and $\mathrm{Xgwm} 332^{\mathrm{Y}}$ & 1 & 62 & 45 \\
\hline
\end{tabular}

${ }^{a}$ Their optimum profile ( $P$, as detailed in material and methods), annealing temperature $\left(T^{\mathrm{m}}\right)$ and number of cycles $(n)$ are indicated. For each SSR, it is specified the genotype of the pre-ILs: if the allele of 'Yavaros' was present in all pre-ILs $\left({ }^{Y}\right)$, if it was the allele of $T$. urartu $\left({ }^{\mathrm{U}}\right)$ or if the locus was segregating $\left({ }^{\mathrm{S}}\right)$. 

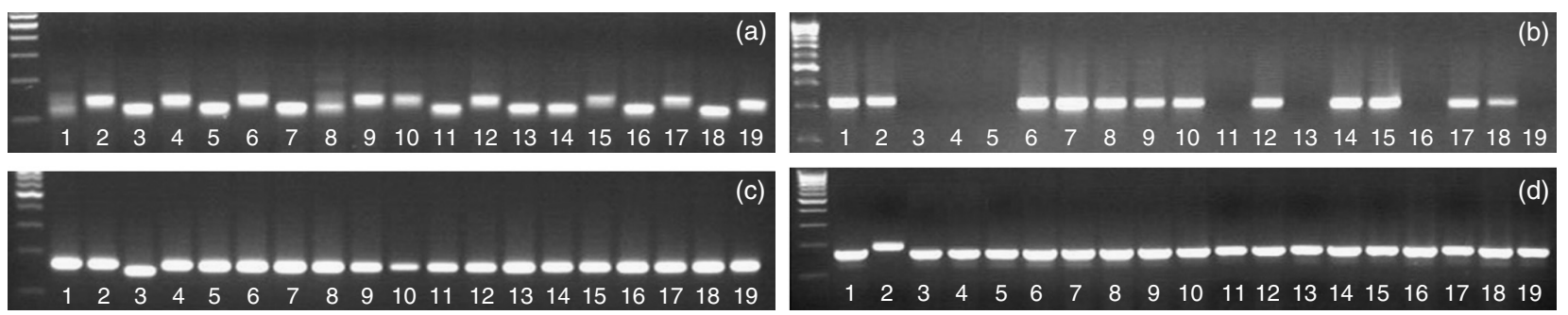

Fig. 2. Amplification of SSR markers XBARC108 (a), Xgwm136 (b), Xgwm674 (c) and Xwmc658 (d) in the following lines: (1) founder line, (2) T. turgidum ssp. durum cv. 'Yavaros', (3) T. urartu accession MG26992 and (4-19) pre-ILs 1-31.

(55.6 and 50\%, respectively), alleles of T. urartu were identified. Lower rates of introgression were observed in chromosomes $3 \mathrm{~A}$ and 5A, with 14.3 and 33.3\%, respectively. Finally, no introgressions from T. urartu were detected in chromosomes $4 \mathrm{~A}$ and $6 \mathrm{~A}$.

The set of SSRs selected for this work are useful for defining eighteen chromosomal reference points (CRPs), where introgressions of T. urartu into durum wheat have occurred in the pre-ILs. Introgressed fragments of T. urartu were identified in chromosomes 1A, 2A, 3A, 5A and 7A (Supplementary Table S2, available online only at http://journals.cambridge.org).

\section{Discussion}

In this work, we present a core collection of SSRs which have shown themselves to be very useful for different purposes: (1) Genotyping the pre-ILs: the strategic location of the 57 SSRs gives an overview of the genetic composition of the pre-ILs. Now, this valuable material is well characterized and ready to be used for research purposes by any durum wheat breeder; (2) defining CRPs: the selected SSRs define 18 CRP in chromosomes 1A, 2A, 3A, 5A and 7A (Supplementary Table S2, available online only at http://journals.cambridge.org), targeting the introgressed regions (3) estimating the introgression rates: the exotic germplasm introgressed can also be estimated with the information given by the molecular markers (Table 2). The founder line had been selected according to the presence of variants from $T$. urartu at Glu-A1 locus (Alvarez et al., 2009), located in chromosome 1A (Payne et al., 1980; Lawrence and Shepherd, 1981). The selection pressure exerted has been very effective as revealed by the introgression rates observed in chromosome $1 \mathrm{~A}$, where the highest variation derived from T. urartu has been identified (Table 2 and Supplementary Table S2, available online only at http:// journals.cambridge.org). Indeed, alleles from $T$. urartu were detected at all the loci tested in chromosome 1A within the set of pre-ILs. Therefore, a single selection step during the development of the founder line using protein markers was enough to maximize the variation within chromosome $1 \mathrm{~A}$, while reducing the variability in the rest of the chromosomes, as expected. For the rest of the chromosomes (where selection has not been exerted), introgressions have occurred at random, and, obviously, the introgressions present in the pre-ILs depend on the genotype of the founder line selected. This results in moderate or low introgression rates (in chromosomes $2 \mathrm{~A}$ and $3 \mathrm{~A}$, respectively) or in no introgressions events at all (the case of chromosome 6A).

Table 2. Exotic germplasm introgressed in durum wheat 'Yavaros', estimated by the presence of alleles of $T$. urartu at each of the polymorphic loci analyzed in chromosomes $1 \mathrm{~A}$ to $7 \mathrm{~A}$ within the 98 pre-ILs

\begin{tabular}{lccccc}
\hline Chromosome & $\begin{array}{c}\text { Polymorphic } \\
\text { SSRs }\end{array}$ & $\begin{array}{c}\text { Genotype } \\
\text { 'Yavaros' }^{-}\end{array}$ & $\begin{array}{c}\text { Genotype } \\
\text { T. urartu }\end{array}$ & Segregating & $\begin{array}{c}\text { Exotic } \\
\text { germplasm } \\
\text { introgressed } \\
(\%)^{\mathrm{a}}\end{array}$ \\
\hline 1A & 9 & 0 & 0 & 9 & 100 \\
2A & 9 & 4 & 2 & 3 & 55.6 \\
3A & 7 & 6 & 0 & 1 & 14.3 \\
4A & 7 & 7 & 0 & 0 & - \\
5A & 9 & 6 & 1 & 2 & 33.3 \\
6A & 8 & 8 & 0 & 0 & - \\
7A & 8 & 4 & 3 & 1 & 50 \\
\hline
\end{tabular}

${ }^{\mathrm{a}}$ Determined as the ratio: loci with alleles from T. urartu/total polymorphic loci. 
Regarding chromosome 4A, the absence of introgressions of $T$. urartu can be explained because, as has been described (Chapman et al., 1976; Dvořák, 1976), neither chromosome $4 \mathrm{~A}$ nor chromosome $4 \mathrm{~B}$ of wheat pairs with any of the T. urartu chromosomes; (4) markerassisted selection: marker-assisted selection will enable the isolation of introgressions from T. urartu to obtain a set of ILs for chromosome 1A. In addition, it would be expectable that repeating the backcross between the amphiploid and durum wheat, selecting for chromosome number and using these SSR markers, the variability found in a specific chromosome would be maximized, while the number of introgressions in the other chromosomes would be reduced. Thus, a single selection step would suffice to increase the efficiency of introgression of any T. urartu chromosome into durum wheat by selecting new founder lines.

There is increasing evidence of the presence of beneficial alleles in the wild relatives which are hidden by other deleterious alleles (Huang et al., 2003; Matus et al., 2003). This natural variation available in the wild ancestors can be exploited in durum wheat. T. urartu may be useful for durum wheat breeding since it is possible to develop ILs using an amphiploid as a genetic bridge. Considering the success of synthetic wheats, it would seem of interest to develop similar programmes for durum wheat using T. urartu. From the present study, a set of 57 polymorphic A-genome wheat-specific markers have been identified as being useful for T. urartu-wheat marker-assisted introgression breeding. These results would allow a more effective selection of new ILs aiming to maximize variability in other chromosomes for genetic studies.

\section{Acknowledgements}

This work has been performed with the financial support of the Spanish Ministry of Science and Innovation (AGL2009-11359) and the Consejería de Economía, Innovación y Ciencia of the Junta de Andalucía (P09AGR-4817) and FEDER. C. R.-S. acknowledges financial support from CSIC (JAE-Doc program). We are grateful to E. León for her technical assistance.

\section{References}

Alvarez JB, Caballero L, Nadal S, Ramirez CM and Martín A (2009) Development and gluten strength evaluation of introgression lines of Triticum urartu in durum wheat. Cereal Research Communications 37: 243-248.

Atienza SG, Ramirez CM, Hernandez P and Martin A (2004) Chromosomal location of genes for carotenoid pigments in Hordeum chilense. Plant Breeding 123: 303-304.
Atienza S, Avila CM and Martín A (2007a) The development of a PCR-based marker for PSY1 from Hordeum chilense, a candidate gene for carotenoid content accumulation in tritordeum seeds. Australian Journal of Agriculture Research 58: 767-773.

Atienza SG, Ballesteros J, Martin A and Hornero-Mendez D (2007b) Genetic variability of carotenoid concentration and degree of esterification among tritordeum ( $\times$ Tritordeum Ascherson et Graebner) and durum wheat accessions. Journal of Agricultural and Food Chemistry 55: 4244-4251.

Börner A, Schumann E, Fürste A, Cöster H, Leithold B, Röder M and Weber W (2002) Mapping of quantitative trait loci determining agronomic important characters in hexaploid wheat (Triticum aestivum L.). Theoretical and Applied Genetics 105: 921-936.

Brondani C, Rangel PHN, Brondani RPV and Ferreira ME (2002) QTL mapping and introgression of yield-related traits from Oryza glumaepatula to cultivated rice (Oryza sativa) using microsatellite markers. Theoretical and Applied Genetics 104: 1192-1203.

Carmona S, Caballero L, Martín LM and Alvarez JB (2010) Genetic diversity in khorasan and rivet wheat by assessment of morphological traits and seed storage proteins. Crop and Pasture Sciences 61: 938-944.

Chapman V, Miller TE and Riley R (1976) Equivalence of the A genome of bread wheat and that of Triticum urartu. Genetics Research 27: 69-76.

di Pietro JP, Caillaud CM, Chaubet B, Pierre JS and Trottet M (1998) Variation in resistance to the grain aphid, Sitobion avenae (Sternorhynca: Aphididae), among diploid wheat genotypes: multivariate analysis of agronomic data. Plant Breeding 117: 407-412.

Dvoŕák J (1976) The relationship between the genome of Triticum urartu and the A and B genomes of Triticum aestivum. Canadian Journal of Genetics and Cytology 18: $371-377$.

Eshed Y and Zamir D (1994) A genomic library of Lycopersicon pennellii in L. esculentum: a tool for fine mapping of genes. Euphytica 79: 175-179.

Fetch TG Jr, Steffenson BJ and Nevo E (2003) Diversity and sources of multiple disease resistance in Hordeum spontaneum. Plant Disease 87: 1439-1448.

Huang XQ, Coster H, Ganal MW and Röder MS (2003) Advanced backcross QTL analysis for the identification of quantitative trait loci alleles from wild relatives of wheat (Triticum aestivum L.). Theoretical and Applied Genetics 106: $1379-1389$.

Huang XQ, Kempf H, Ganal MW and Röder MS (2004) Advanced backcross QTL analysis in progenies derived from a cross between a German elite winter wheat variety and a synthetic wheat (Triticum aestivum L.). Theoretical and Applied Genetics 109: 933-943.

Lawrence GJ and Shepherd KW (1981) Inheritance of glutenin protein subunits of wheat. Theoretical and Applied Genetics 60: 333-337.

Lee M (1998) Genome projects and gene pools: new germplasm for plant breeding? Proceedings of the National Academy of Sciences of the United States of America 95: 2001-2004.

Martín MA, Martín LM and Alvarez JB (2008) Polymorphisms at the Gli-Au1 and Gli-Au2 loci in wild diploid wheat (Triticum urartu). Euphytica 163: 303-307.

Matus I, Corey A, Filichkin T, Hayes PM, Vales MI, Kling J, Riera-Lizarazu O, Sato K, Powell W and Waugh R (2003) 
Development and characterization of recombinant chromosome substitution lines (RCSLs) using Hordeum vulgare subsp. spontaneum as a source of donor alleles in a Hordeum vulgare subsp. vulgare background. Genome 46: 1010-1023.

Murray YHG and Thompson WF (1980) Rapid isolation of high molecular weight plant DNA. Nucleic Acids Research 8: 4321-4326.

Payne PI, Law CN and Mudd EE (1980) Control by homeologous group I chromosomes of the high molecular weight subunits of glutenin, a major protein of wheat endosperm. Theoretical and Applied Genetics 58: 113-120.

Pestsova E, Börner A and Röder MS (2006) Development and QTL assessment of Triticum aestivum-Aegilops tauschii introgression lines. Theoretical and Applied Genetics 112: 634-647.

Piergiovanni AR (2009) Estimating gliadin and albumin variation at intra- and interaccession level in USDA oriental wheat (Triticum turgidum L. subsp. turanicum (Jakubz.) (A. Lőve \& D. Lőve) collection using capillary zone electrophoresis. Cereal Chemistry 86: 37-43.

Qiu YC, Zhou RH, Kong XY, Zhang SS and Jia JZ (2005) Microsatellite mapping of a Triticum urartu Tum. derived powdery mildew resistance gene transferred to common wheat (Triticum aestivum L.). Theoretical and Applied Genetics 111: 1524-1531.

Röder MS, Korzun V, Wendehake K, Plaschke J, Tixier MH, Leroy P and Ganal MW (1998) A microsatellite map of wheat. Genetics 149: 2007-2023.

Rodríguez-Suárez C, Giménez MJ and Atienza SG (2010) Progress and perspectives for carotenoid accumulation in selected Triticeae species. Crop and Pasture Sciences 61: $743-751$.

Somers DJ, Isaac P and Edwards K (2004) A high-density wheat microsatellite consensus map for bread wheat (Triticum aestivum L.). Theoretical and Applied Genetics 109: 1105-1114.

Sourdille P, Singh S, Cadalen T, Brown-Guedira GL, Gay G, Qi L, Gill BS, Dufour P, Murigneux A and Bernard M (2004) Microsatellite-based deletion bin system for the establishment of genetic-physical map relationships in wheat (Triticum aestivum L.). Functional and Integrative Genomics 4: 12-25.

Tanksley SD and McCouch SR (1997) Seed banks and molecular maps: unlocking genetic potential from the wild. Science 277: 1063-1068.

van Ginkel M and Ogbonnaya F (2007) Novel genetic diversity from synthetic wheats in breeding cultivars for changing production conditions. Field Crops Research 104: 86-94.

Warburton ML, Crossa J, Franco J, Kazi M, Trethowan R, Rajaram S, Pfeiffer W, Zhang P, Dreisigacker S and van Ginkel M (2006) Bringing wild relatives back into the family: recovering genetic diversity in CIMMYT improved wheat germplasm. Euphytica 149: 289-301.

Young ND and Tanksley SD (1989) Restriction fragment length polymorphism maps and the concept of graphical genotypes. Theoretical and Applied Genetics 77: 95-101.

Yun SJ, Gyenis L, Hayes PM, Matus I, Smith KP, Steffenson BJ and Muehlbauer GJ (2005) Quantitative trait loci for multiple disease resistance in wild barley. Crop Sciences 45: 2563-2572.

Xu LL, Li W, Wei YM and Zheng YL (2009) Genetic diversity of HMW glutenin subunits in diploid, tetraploid and hexaploid Triticum species. Genetic Resources and Crop Evolution 56: 377-391.

Zhang W, Lukaszewski AJ, Kolmer J, Soria MA, Goyal S and Dubcovsky J (2005) Molecular characterization of durum and common wheat recombinant lines carrying leaf resistance (Lr19) and yellow pigment $(Y)$ genes from Lophopyrum ponticum. Theoretical and Applied Genetics 111: 573-582. 